\title{
Positive orientation as a predictor of hedonic well-being: mediating role of the self-concept
}

\section{BACKGROUND}

Positive orientation (PO) is a hidden variable explaining a tendency to formulate global evaluations regarding one's self, life and the future. It is inherited to a large degree and it could be considered a common base for numerous aspects of subjective well-being. The self-concept, in turn, is a basic adaptation formed during individual experiences that is responsible for adjustment. The primary aim of the current study was to verify hypotheses about the significant relationship between PO and a "core self" (high self-concept clarity, low self-esteem contingency, low self-rumination), as well as the meditational role of the "core self" in the relation between PO and hedonic balance.

\section{PARTICIPANTS AND PROCEDURE}

A group of 200 participants completed several measures referring to $\mathrm{PO}$, self-concept and emotions.

\section{RESULTS}

The canonical correlation analysis revealed $\mathrm{PO}$ to be a strong predictor of the adaptive features of the self-concept. Moreover, the tested models suggest that (1) self-concept clarity is a significant mediator between PO and hedonic balance, and (2) PO directly predicts only self-concept clarity, whereas its relations with self-esteem contingency and rumination are mediated by the self-knowledge structure.

\section{CONCLUSIONS}

These findings indicate that PO is an important and independent factor enhancing adaptive features of the self-concept structure as well as well-being.

\section{KEY WORDS}

positive thinking; self-concept clarity; rumination; contingent self-esteem; hedonic balance

ORganisation - 1: Institute of Psychology, The John Paul II Catholic University of Lublin, Poland · 2: Nicolaus Copernicus University in Toruń, Poland

Authors' COntributions - A: Study design - B: Data collection - C: Statistical analysis · D: Data interpretation .

E: Manuscript preparation · F: Literature search · G: Funds collection

CORresPonding AUthor - Agnieszka Anna Laskowska, Ph.D., Institute of Psychology, The John Paul II Catholic

University of Lublin, 14 Racławickie Avenue, 20-950 Lublin, Poland, e-mail: laskowska.agnieszkaanna@gmail.com

To Cite this ARTICle - Laskowska, A. A., Jankowski, T., Oleś, P., \& Miciuk, Ł. (2018). Positive orientation as a predictor

of hedonic well-being: mediating role of the self concept. Health Psychology Report, 6(3), 261-272. doi: https://doi.

org/10.5114/hpr.2018.75752

RECEIVED 12.12.2017 · REVIEWED · 02.02.2018 · ACCEPTED 02.05.2018 • PUBLISHED 08.06.2018 


\section{BACKGROUND}

Positive psychology, which has been intensively developed in recent decades, puts an individual's strong points into the research spotlight. Researchers in the field of positive psychology proposed a new social-cognitive view of the human being, offering more in-depth knowledge about the joys of life, happiness, well-being and life satisfaction. Such constructs as self-esteem (Rosenberg, 1965), life satisfaction (Diener, 1984) and optimism (Scheier, Carver, \& Bridges, 1994), seem to be the most frequently investigated phenomena within the field (Baumeister, Campbell, Krueger, \& Vohs, 2003; Kernis, 2003; Caprara, Steca, Gerbino, Paciello, \& Vecchio, 2006; Diener, Fujita, Tay, \& Biswas-Diener, 2012). Recent investigations suggest that these phenomena, which are commonly associated with health assessment, well-being or success, can also be used to indicate an individual's positive judgments about the self, world and future called positive orientation - PO (Caprara et al., 2012a).

The aim of this study is (1) to check to what extent $\mathrm{PO}$ and adaptive features of the self (such as self-concept clarity, self-reflection versus self-rumination and non-contingency of self-esteem) share common variance in young adults, and (2) to verify a model of relationships among several variables related to $\mathrm{PO}$ and adaptive features of the self-concept using path analysis. Both sets of variables, labeled "positive orientation" and "adaptive features of the self", relate to personal development, growth, and well-being. Thus, their mutual relationships are important to learn about psychological conditions facilitating optimal functioning (see e.g. Deci \& Ryan, 2008; Fredrickson, 2009; Peterson \& Seligman, 2004).

\section{POSITIVE ORIENTATION}

Empirical findings focused on self-esteem, life satisfaction and optimism show that these three variables share most of the common variance. Results of studies over the last few years also suggest that these variables that were traditionally considered to be social-cognitive in their origin and nature actually have a common genetic basis (Caprara et al., 2009). These findings also proved that self-esteem, life satisfaction and optimism can be traced to a higher-order dimension labeled positive orientation (Alessandri, Caprara, \& Tisak, 2012; Caprara, 2009; Caprara et al., 2009). Positive orientation is a basic predisposition to perceive and evaluate positive aspects of life, the future and oneself (Caprara, 2009) and it seems to be a reliable construct across different cultures, such as Italy, Canada, German and Japan (Caprara et al., 2012b; Heikamp et al., 2014; Miciuk, Jankowski, Laskowska, \& Oleś, 2016). Longitudinal studies revealed that $\mathrm{PO}$ has a nonlinear relation with age, with its peak in the middle adulthood period (Caprara et al., 2012a).

Recent research (e.g. Caprara \& Steca, 2005; Oleś et al., 2013) has focused on the question of whether other 'positive' constructs might compose PO together with self-esteem, optimism and life satisfaction. For example, Oleś and colleagues (2013) demonstrated that PO and generalized self-efficacy constitute two separate but correlated constructs. However, other links between PO and positive features of the self-system, for example self-concept clarity, have not been investigated until now.

In the article by Oleś and Jankowski (2018) a broader understanding of $\mathrm{PO}$ conceptualized as a latent factor, underlying variables that exemplify a hedonistic and eudemonistic view of happiness, was tested. Their results suggested that PO can be treated as a general factor constituting the basis for integrating two aspects of well-being: looking for positivity and pleasure, and struggling for meaning. Other researchers concentrated on the moderation analysis of positivity. It was revealed that it is positivity, both at the individual level and in cross-level interactions, that moderates the relationship between positive goal-oriented affect and personal goal realization (Laguna, Alessandri, \& Caprara, 2017). Positivity, conceptualized as a general inclination to react to life experiences in a positive approach, predicted chronic positive affectivity across time rather than vice versa (Caprara, Eisenberg, \& Alessandri, 2017). Other researchers focused on positive orientation as a mediator. The effect of extraversion on happiness was fully mediated by positivity, whilst the effect of neuroticism was only partially mediated (Lauriola \& Iani, 2015). Another study showed that the general positivity factor completely mediated neuroticism-subjective happiness relationships and overlapped with general neuroticism, whereas it partially mediated extraversion-subjective happiness relationships (Lauriola \& Iani, 2017). The latest findings indicated that, among emotion regulation strategies, internal dysfunctional emotion regulation strongly mediated between perceived stress and positivity (Yildiz, 2017).

\section{ADAPTIVE FEATURES OF SELF-CONCEPT}

Self-concept can be defined as an organized scheme containing episodic and semantic memory on the subject of the self, which controls information processing that is concerned with the self (see Leary \& Tangney, 2012). As such, the self-concept has various aspects, and can be analyzed from different, yet complementary, perspectives: structural, evaluative and motivational. Although there are numerous variables that describe self-concept features, some of them are more important for well-being and adjustment (see Campbell, Assanand, \& Di Paula, 2003). 
The structural aspect of self-concept refers to the complexity and unity of self-knowledge. Several studies have found that integrity of self-knowledge, as defined in terms of self-clarity (a concept expressing the degree to which one's self-concept is internally coherent, stable and confidently defined; Campbell et al., 1996), is consistently and positively related to well-being (Campbell et al., 2003). On the other hand, self-complexity (the number and redundancy of self-aspects; Linville, 1985) and self-compartmentalization (the degree to which one's positive and negative self-knowledge are separated into uniformly valenced categories; Showers, 2002), are not related to optimal functioning (Campbell et al., 2003).

The dynamic aspect of self-concept refers to motives that influence the content and form of self-awareness. Trapnell and Campbell (1999) proposed two different styles of processing self-relevant information based on different motivations: rumination and reflection. The former is usually induced by anxiety and self-uncertainty, while the latter is related to self-curiosity and philosophical attitudes toward the self. Both kinds of self-awareness are significantly but contradictorily related to well-being: while rumination strongly and negatively predicts optimal functioning, reflection predicts it positively but weaker than does rumination (Trapnell \& Campbell, 1999).

The third aspect of self-concept refers to the evaluative processes that are expressed in the positive or negative attitudes toward the self. According to Kernis' conception of optimal self-esteem (Kernis, 2003), a self-attitude can be analyzed taking into account its positivity/negativity dimensions, as well as its conditional/unconditional features. Therefore, optimal self-esteem is defined as a positive and non-contingent (i.e. stable) attitude toward the self, and, as such, it is an important predictor of effective self-regulation and mental health (e.g. Crocker, Brook, Niiya, \& Villacorta, 2006).

A review of the research on various aspects of self-concept shows that high self-concept clarity, low contingency of self-esteem, low rumination, and moderate reflection are significantly related to each other and to various aspects of well-being (e.g. Campbell et al., 1996; Jankowski, 2008). Therefore, we propose that non-ruminative ways of thinking, together with clarity of self-knowledge and stable self-esteem, are the basis for the adaptive way of experiencing the self that facilitates effective self-regulation and satisfactory interpersonal relations. It resembles the concept of "true self", developed by Ryan (1995); however, we emphasize cognitive features of the self (e.g. its structure, self-awareness processes, etc.), while the "true self" refers mainly to the broader theory of motivation, namely self-determination theory (Deci \& Ryan, 2000).
POSITIVE ORIENTATION, ADAPTIVE FEATURES OF SELF-CONCEPT AND WELL-BEING

On one hand we know about a general inclination for positive thinking about the self, life and future called positive orientation, while on the other hand we know some characteristics of adaptive self-knowledge, its organization and functioning. The question is how these two aspects are interrelated. There are numerous results showing relationships between particular components of $\mathrm{PO}$ and the adaptive features of the self-concept. For example, self-concept clarity is substantially correlated with self-esteem measures - individuals higher in clarity were also higher in self-esteem (Campbell et al., 1996; see also Baumeister et al., 2003; Kernis, 2006). Self-concept clarity is also positively related to life satisfaction, and both variables are negatively correlated with neuroticism and stress (Ritchie, Sedikides, Wildschut, Arndt, \& Gidron, 2011). Cross-sectional findings on the relationship between self-esteem and rumination suggest negative correlations between them. Low self-esteem does predict subsequent rumination and the latter also predicts subsequent depression. It allows one to hypothesize that rumination might be a partial mediator of the prospective effect of low self-esteem on depression (Kuster, Ortch, \& Meier, 2012). Some studies also show that contingent self-esteem is correlated negatively with life satisfaction and with psychological well-being (Kernis, Lakely, \& Heppner, 2008).

Numerous studies suggest that the level of self-esteem is also related to happiness (e.g. Diener \& Diener, 1995; Kernis, 2006). Moreover, some other studies suggest a positive correlation of self-esteem and positive affect, as well as a negative correlation with negative affect (e.g. Watson, Suls, \& Haig, 2002). A study by Caprara and Steca (2005) revealed strong positive correlations between hedonic balance measured as differences between positive and negative affect $(\mathrm{P}-\mathrm{N})$ and all components of PO: self-esteem, life satisfaction and optimism. Moreover, several studies have shown that low self-concept clarity also predicts negative affect, anxiety, and depression (Campbell et al., 2003; Campbell et al., 1996). Rumination is not only moderately related to negative affect and neuroticism (Trapnell \& Campbell, 1999), but it is also a negative predictor of other aspects of well-being (such as autonomy, self-acceptance and positive relations with others) (Harrington \& Loffredo, 2011) as well as an important risk factor for hard-to-treat depression (e.g. Nolen-Hoeksema, 2000). Contingent self-esteem also predicts symptoms of depression (Sargent, Crocker, \& Luhtanen, 2006), and verbal defensiveness and intensity of anger aroused by ego-threat (Kernis et al., 2008).
Positive orientation and the self-concept 


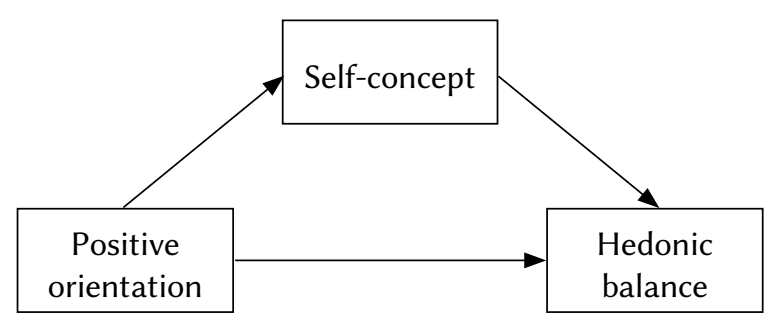

Figure 1. A conceptual model of the mediatory role of the self-concept in the relationship between positive orientation and hedonic balance.

Laskowska,

Tomasz Jankowski, Piotr Oleś,

Łukasz Miciuk

\section{CURRENT STUDY}

In the study we explore the relationship between $\mathrm{PO}$ and adaptive features of self. We hypothesize that $\mathrm{PO}$, composed of self-esteem, satisfaction with life and optimism, is positively correlated with self-concept clarity and reflection, and negatively correlated with rumination and contingent self-esteem. Both sets of variables are directly or indirectly related to the self, but they represent different aspects of it. For example, self-esteem emphasizes content and valence of information about the self (its positivenegative quality), and the notion of self-concept clarity refers not to the contents of self-concept, but rather the way information about the self is organized.

The second aim of the study is to assess the relative meaning of $\mathrm{PO}$ and adaptive aspects of the self (i.e. self-concept clarity, non-rumination and unconditional self-esteem) in predicting hedonic balance (i.e. the difference between positive and negative affect, PA - NA). The results briefly reviewed above suggest that both $\mathrm{PO}$ and the adaptive features of the self-concept play important roles in predicting well-being. If we assume - using concepts of McCrae and Costa's (1999) theory of personality - that PO is a kind of "basic tendency", while the particular features of the self-concept are "adaptations" influenced both by PO and some external factors (e.g. the social environment), we can postulate that the latter variable at least partially mediates the relationship between $\mathrm{PO}$ and hedonic balance (Figure 1).

\section{PARTICIPANTS AND PROCEDURE}

\section{PARTICIPANTS}

The test group consisted of students $(N=200)$ from different parts of Poland. The participants were between 19 and 31 years old, and average age was $M=22.77$ years. The mean age for females was $M=22.89, S D=2.35$ and for males $M=22.65$,
$S D=2.43$. The majority of the participants were single $(94.50 \%)$, some of them are married $(5.00 \%)$ and only a few divorced $(0.50 \%)$.

\section{PROCEDURE}

During the survey, 248 questionnaires were distributed and 211 were returned. Eleven of them were rejected because of a significant amount of missing data (e.g. lack of a whole scale). The results were obtained based on 200 surveys (50\% of women). The participants were recruited using the snowball sampling method, a non-probability sampling technique where existing subjects were also encouraged to recruit their acquaintances to participate. To avoid the social desirability effect as much as possible, respondents were informed that their participation was voluntary and confidential.

\section{MEASURES}

To measure PO, three instruments were administered: the Self-Esteem Scale, the Satisfaction with Life Scale and the Life Orientation Test-Revised.

Rosenberg's Self-Esteem Scale (SES) is a one-dimensional tool that measures the level of global self-esteem (Rosenberg, 1965). It consists of $10 \mathrm{di}$ agnostic questions. The questions are answered on a 4-item scale, whose anchors range from 1 (strongly agree) to 4 (strongly disagree). In the current study, Cronbach's $\alpha$ is .86 .

The Satisfaction with Life Scale (SWLS) is a 5-item measurement of an individual's global appraisal of life satisfaction (Diener, Emmons, Larsen, \& Griffin, 1985). Responses are rated on a 7-point Likert scale. In the current study, Cronbach's $\alpha$ is .82 .

The Life Orientation Test-Revised (LOT-R) consists of 10 assertions measuring optimism on a 5-point response scale (Scheier et al., 1994), with six being diagnostically relevant, and four serving as masking (buffer) positions. The aggregate test result is a sum of the evaluation of six assertions, with three being positive and three negative. In the current study, Cronbach's $\alpha$ is .78.

To measure particular features of adaptive self and well-being, we used the Self Concept Clarity Scale, the Rumination-Reflection Questionnaire, the Contingent Self-Esteem Scale, and the Positive and Negative Affect Schedule-Expanded Form.

The Self-Concept Clarity Scale (SCCS; Campbell et al., 1996) is a self-report measure of the extent to which individuals have a well-defined, coherent, and stable sense of self. The scale has 12 items, rated on a 5-point Likert scale (e.g.: "I seldom experience conflict between the different aspects of my personality”). In the current study, Cronbach's $\alpha$ is .90. 
The Rumination-Reflection Questionnaire (RRQ) measures two different forms of self-consciousness: rumination and reflection. The first measures the individual's tendency to repeatedly self-focus on past actions, whereas the latter measures the philosophical love of self-exploration (Trapnell \& Campbell, 1999). The RRQ contains self-rumination and self-reflection subscales. Each subscale consists of 12 items. Participants respond using a 5-point Likert scale (e.g.: "Sometimes it is hard for me to shut off thoughts about myself" for rumination) and "I love exploring my 'inner' self” for reflection). In this way, for each scale, the minimum result is 12 , whereas the maximum is 60 . In this study, the alphas are .91 and .93 respectively.

The Contingent Self-Esteem Scale (CSES) examines the conditioning of self-esteem, meaning the degree to which its level depends on the situational inflow of evaluative information, such as successes, failures and laudatory or unflattering opinions of others (Paradise \& Kernis, 1999). The questionnaire consists of 15 assertions rated by the subject on a 5-point scale (e.g.: "An important measure of my worth is how competently I perform"). An overall score is obtained in the range of 15 to 75 . In this study, Cronbach's $\alpha$ is .87.

In order to assess positive and negative affect, a Polish adaptation (Fajkowska \& Marszał-Wiśniewska, 2009) of the Positive and Negative Affect Schedule - Expanded Form (PANAS-X) was used (Watson \& Clark, 1994). The PANAS-X measures General PA (e.g. proud, excited, etc.) and NA (e.g. frightened, hostile, etc.) as well as three facets of PA (Joviality, Self-Assurance, and Attentiveness) and four facets of NA (Fear, Sadness, Guilt, and Hostility). The participants were asked to rate their general affective states on a five-point response scale from $1=$ very slightly to $5=$ extremely. The Cronbach's $\alpha$ coefficients were .81 for the positive effect subscale and .91 for the negative affect subscale. The PANAS-X also allows calculation of the single index of affect, named hedonic balance $(\mathrm{P}-\mathrm{N})$. It means the difference between PA and NA; the higher the score in hedonic balance, the greater is the predominance of PA over NA.

\section{DATA ANALYSIS}

In line with the two-fold aim of this study, we adopted two approaches to analyze relationships between positive orientation, self-concept and affectivity. Firstly, to discover relations between variables that constitute positive orientation and variables which describe important aspects of a self-concept, we performed canonical correlation analysis (CCA). Although CCA is mainly an exploratory technique, we assumed that treating self-esteem, optimism and satisfaction with life as one set of variables leads to computing a latent variable which can be identified with positive orientation. In this way we can check its correlation with the other latent variable created from such variables as self-concept clarity, rumination, reflection and contingent self-esteem. Thus, in one analysis we can discover a specific pattern of relationships between these two sets of variables.

To analyze the meaning of self-concept as a mediator of the relationship between positive orientation and hedonic balance (see Figure 1), we decided to perform a serial multiple mediator model following Preacher and Hayes' suggestions (2008). In this kind of model, a predictor causes a dependent variable via one, albeit complex mediation path including several mutually dependent variables. We hypothesized that (1) positive orientation facilitates forming a clear self-concept, which (2) reduces the level of instability of self-esteem, which in turn (3) reduces uncertainty and rumination. Thus, we expect that positive orientation finally improves hedonic balance partly via the path leading from self-concept clarity, to contingent self-esteem and to rumination. To verify this model and estimate its coefficients, we performed ordinary least square path analysis. Additionally a bootstrapping procedure was employed to generate confidence intervals [CI] for mediation effects. Bootstrapping is recommended as the most effective method to use with small samples and/or non-normally distributed data, and it significantly reduces the risk of type I errors. Based on this analysis we could estimate direct, indirect and total effects of PO on hedonic balance. We also specified several alternative models in which we retained PO as the main predictor and hedonic balance as a dependent variable, but we allowed for various causal paths relating self-concept, contingent self-esteem and rumination. To evaluate model fit we used two commonly used indices, the confirmatory fit index (CFI) and the root mean square error of approximation (RMSEA). To confirm good fit of data we accepted Hu and Bentler's (1999) suggestions that CFI should be higher than .95 and RMSEA should be lower than .06. To compare models we used the Akaike information criterion (AIC). The smallest AIC suggests the best fitting model (Burnham \& Anderson, 2002).

\section{RESULTS}

Positive orientation was examined using three different scales measuring self-esteem, optimism and life satisfaction. An exploratory factor analysis (EFA) conducted on the total scores from the three aforementioned scales was used to obtain a general factor score of PO. Factor loadings of self-esteem and optimism were equal (.87), and loading of satisfaction with life was slightly lower (.82). Positive orientation as a factor explained $72.00 \%$ of the variance of the three aforementioned variables.
Positive orientation and the self-concept 
Table 1

Descriptive statistics

\begin{tabular}{lcccc}
\hline Variable & \multicolumn{4}{c}{ Total $(N=200)$} \\
\cline { 2 - 5 } & $M$ & $S D$ & $\min$ & $\max$ \\
\hline Self-esteem & 30.30 & 4.54 & 17.00 & 40.00 \\
Life satisfaction & 20.91 & 5.72 & 6.00 & 35.00 \\
Optimism & 15.61 & 4.66 & 4.00 & 24.00 \\
$\begin{array}{l}\text { Positive orienta- } \\
\text { tion }\end{array}$ & $0.00^{\wedge}$ & $1.00^{\wedge}$ & -2.91 & 2.03 \\
$\begin{array}{l}\text { Self-concept } \\
\text { clarity }\end{array}$ & 38.42 & 9.76 & 14.00 & 60.00 \\
$\begin{array}{l}\text { Rumination } \\
\text { Reflection }\end{array}$ & 41.81 & 9.34 & 16.00 & 60.00 \\
$\begin{array}{l}\text { Contingent } \\
\text { self-esteem }\end{array}$ & 38.24 & 9.97 & 13.00 & 60.00 \\
$\begin{array}{l}\text { Negative affect } \\
\text { Positive affect }\end{array}$ & 25.48 & 8.18 & 11.00 & 49.00 \\
$\begin{array}{l}\text { Hedonic balance } \\
\text { Hediny }\end{array}$ & 8.52 & 10.05 & -23.00 & 35.00 \\
\hline
\end{tabular}

Note. Positive orientation measured as a factor score (self-esteem, life satisfaction and optimism).

${ }^{\wedge}$ Results of PO are standardized.
Table 1 presents the means and standard deviation for all measures included in the study.

To verify the relationship between $\mathrm{PO}$ and the adaptive features of the self-concept, we conducted both intercorrelations between particular variables ( $r$ Pearson) and canonical correlations between two sets of variables: connected to PO versus connected to self-concept. Table 2 presents the intercorrelations between the variables. Positive orientation measured as a factor score corresponds moderately and positively with self-concept clarity but negatively with rumination. Weaker, but still statistically significant, negative relationships can be observed between $\mathrm{PO}$ and contingent self-esteem. Moreover, reflection shows a moderate negative relationship with PO.

A canonical correlation analysis (Sherry \& Henson, 2005) was conducted using the four self-concept variables as predictors of the three positive orientation variables to evaluate the multivariate shared relationship between the two variable sets (i.e., self-concept and positive orientation). The analysis yielded three functions with squared canonical correlations $\left(\mathrm{R}_{\mathrm{c}}^{2}\right)$ of .50, .07, .01 for each successive function. Collectively, the full model across all functions was statistically significant using the Wilks' $\lambda=.46$ criterion, $p<.001$. Because Wilks' $\lambda$ represents the variance unexplained by the model, $1-\lambda$ yields the full model effect in an $r^{2}$ metric. Thus, for the set

Table 2

Correlations between variables and Cronbach's $\alpha$

\begin{tabular}{|c|c|c|c|c|c|c|c|c|c|c|}
\hline \multirow[t]{2}{*}{ Variable } & (1) & (2) & (3) & (4) & (5) & (6) & (7) & (8) & (9) & $(10)$ \\
\hline & \multicolumn{10}{|c|}{ Cronbach's $\alpha$} \\
\hline Self-esteem & .86 & & & & & & & & & \\
\hline $\begin{array}{l}\text { Life } \\
\text { satisfaction }\end{array}$ & $.56^{* * *}$ & .82 & & & & & & & & \\
\hline Optimism & $.65^{* * *}$ & $.55^{* * *}$ & .78 & & & & & & & \\
\hline $\begin{array}{l}\text { Positive } \\
\text { orientation }\end{array}$ & $.92^{* * *}$ & $.78^{* * *}$ & $.84^{* * *}$ & & & & & & & \\
\hline $\begin{array}{l}\text { Self-concept } \\
\text { clarity }\end{array}$ & $.70^{* * *}$ & $.40^{* * *}$ & $.47^{* * *}$ & $.64^{* * *}$ & .90 & & & & & \\
\hline Rumination & $-.44^{* * *}$ & $-.33^{* * *}$ & $-.30^{* * *}$ & $-.43^{* * *}$ & $-.61^{* * *}$ & .91 & & & & \\
\hline Reflection & $-.19^{* *}$ & -.05 & -.11 & $-.15^{*}$ & $-.35^{* * *}$ & $.45^{* * *}$ & .93 & & & \\
\hline $\begin{array}{l}\text { Contingent } \\
\text { self-esteem }\end{array}$ & $-.48^{* * *}$ & $-.18^{* *}$ & $-.21^{* *}$ & $-.37^{* * *}$ & $-.57^{* * *}$ & $.54^{* * *}$ & $.29^{* * *}$ & .87 & & \\
\hline $\begin{array}{l}\text { Negative } \\
\text { affect }\end{array}$ & $-.51^{* * *}$ & $-.29^{* * *}$ & $-.39^{* * *}$ & $-.49 * * *$ & $-.53^{* * *}$ & $.45^{* * *}$ & $.30^{* * *}$ & $.45^{* * *}$ & .91 & \\
\hline $\begin{array}{l}\text { Positive } \\
\text { affect }\end{array}$ & $.51^{* * *}$ & $.51^{* * *}$ & $.44^{* * *}$ & $.57^{* * *}$ & $.38^{* * *}$ & $-.26^{* * *}$ & .07 & $-.15^{*}$ & .01 & .81 \\
\hline $\begin{array}{l}\text { Hedonic } \\
\text { balance }\end{array}$ & $.71^{* * *}$ & $.53^{* *}$ & $.57^{* * *}$ & $.73^{* * *}$ & $.65^{* * *}$ & $-.52^{* * *}$ & $-.20^{* *}$ & $-.45^{* * *}$ & $-.81^{* * *}$ & $.58^{* * *}$ \\
\hline
\end{tabular}

Note. Positive orientation as a factor score (self-esteem, life satisfaction and optimism).

${ }^{*} p<.05,{ }^{* *} p<.01,{ }^{* * *} p<.001$ 
Table 3

Canonical solution for self-concept predicting positive orientation for functions 1 and 2

\begin{tabular}{|c|c|c|c|c|c|c|c|}
\hline \multirow[t]{2}{*}{ Variable } & \multicolumn{3}{|c|}{ Function 1} & \multicolumn{3}{|c|}{ Function 2} & \multirow[b]{2}{*}{$h^{2}(\%)$} \\
\hline & Coef & $r_{\mathrm{s}}$ & $r_{s}^{2}(\%)$ & Coef & $r_{s}$ & $r_{s}^{2}(\%)$ & \\
\hline Self-esteem & -0.10 & $-\underline{1.00}$ & 100.00 & 0.89 & $<0.01$ & $<0.01$ & 100.00 \\
\hline Life satisfaction & 0.00 & $-\underline{0.56}$ & 31.47 & -0.96 & $-\underline{0.76}$ & 58.06 & $\underline{89.53}$ \\
\hline Optimism & 0.00 & $-\underline{0.65}$ & 42.12 & -0.54 & $-\underline{0.49}$ & 24.21 & $\underline{66.33}$ \\
\hline$R \mathrm{c}^{2}$ & & & 49.80 & & & & 6.70 \\
\hline Self-concept clarity & -0.91 & $-\underline{0.99}$ & 97.02 & -0.23 & -0.06 & 0.30 & $\underline{97.32}$ \\
\hline Contingent self-esteem & 0.17 & $\underline{0.67}$ & 45.29 & -1.05 & $-\underline{0.53}$ & 28.09 & $\underline{73.38}$ \\
\hline Reflection & -0.12 & 0.27 & 7.18 & -0.45 & -0.24 & 5.71 & 12.89 \\
\hline Rumination & 0.03 & $\underline{0.62}$ & 38.94 & 0.97 & 0.34 & 11.29 & $\underline{50.23}$ \\
\hline
\end{tabular}

Note. Structure coefficients $(r)$ greater than $|.45|$ are underlined. Communality coefficients $\left(h^{2}\right)$ greater than $45 \%$ are underlined. Coef - standardized canonical function coefficient; $r_{s}$ - structure coefficient; $r_{s}^{2}$ - squared structure coefficient; $h^{2}$ - communality coefficient.

of three canonical functions, the $r^{2}$ type effect was .54 , which indicates that the full model explained a substantial portion, about $54.00 \%$, of the variance shared between the variable sets.

Given the $R_{\mathrm{c}}^{2}$ effects for two functions, only the first two functions were considered noteworthy in the context of this study $(49.80 \%$ and $6.70 \%$ of shared variance, respectively).

Table 1 presents the standardized canonical function coefficients and structure coefficients for Functions 1 and 2. The squared coefficients are also given as well as the communalities $\left(h^{2}\right)$ across the two functions for each variable. Looking at Function 1 coefficients, one can see that relevant criterion variables were self-esteem, life satisfaction, and optimism. This conclusion was supported by the squared structure coefficients. Of the positive orientation characteristics, only self-esteem tended to have larger canonical coefficients. A slight exception involved life satisfaction and optimism, which had modest function coefficients but quite large structure coefficients. This result was due to the multicollinearity that these two variables had with the other criterion variables. Furthermore, all of these variables' structure coefficients had the same sign, indicating that they were all positively related.

Regarding the predictor variable set in Function 1, the self-concept clarity variable was the primary contributor to the synthetic variable, with secondary contributions by contingent self-esteem and rumination. Because the structure coefficient for self-concept was negative, it was positively related to all of the positive orientation characteristics. Contingent self-esteem and rumination were positively related to positive orientation. These results were generally supportive of the theoretically expected relationships between adaptive and maladaptive self-concept and positive orientation, and we labeled Function 1 as "positive orientation and self-concept clarity".

Moving on to Function 2, the coefficients in Table 1 suggest that the only criterion variables of relevance were life satisfaction, and optimism, although less so for the latter. These positive orientation characteristics were positively related on this function. As for self-concept, contingent self-esteem was now the dominant predictor. Looking at the structure coefficients for the entire function, it can be seen that contingent self-esteem was positively related to life satisfaction and optimism. Given the nature of these variables, we labeled this function as "the quality of life with negative self-reflection” (Table 3).

A series of regression equations made with the SPSS macro provided by Preacher and Hayes (2008) (with the bootstrap method of estimating confidence intervals, 2000 samples) revealed that PO was a significant direct predictor of hedonic balance even if other variables were controlled $(\beta=.52, p<.001$, $95.00 \%$ CI: $\{.42, .61\})$. We also observed three significant indirect effects of $\mathrm{PO}$ on hedonic balance, mediated by paths through (A) only self-concept clarity $(\beta=.12, p=.007,95.00 \%$ CI: $\{.15, .27\})$, (B) self-concept clarity to rumination $(\beta=.04, p=.027,95.00 \% \mathrm{CI}$ : $\{-.002, .08\})$ and $(\mathrm{C})$ self-concept clarity to contingent self-esteem to rumination $(\beta=.01, p=.048,95.00 \%$ CI: $\{-.001, .03\})$. However, the effects related to paths $\mathrm{B}$ and $\mathrm{C}$ were small and the $95.00 \%$ bootstrap confidence intervals included " 0 ", which means that estimates of these effects could be unreliable. In total, PO explained $53.00 \%$ of hedonic balance (its independent contribution after controlling other variables in the model was $15.00 \%$ ) (Figure 2).

We proposed that PO directly influences self-concept clarity, which is congruent with the theory. Positive attitude toward self, life and future can sta-
Positive orientation and the self-concept 


\section{Agnieszka Anna \\ Laskowska, \\ Tomasz Jankowski, Piotr Oleś, \\ Łukasz Miciuk}

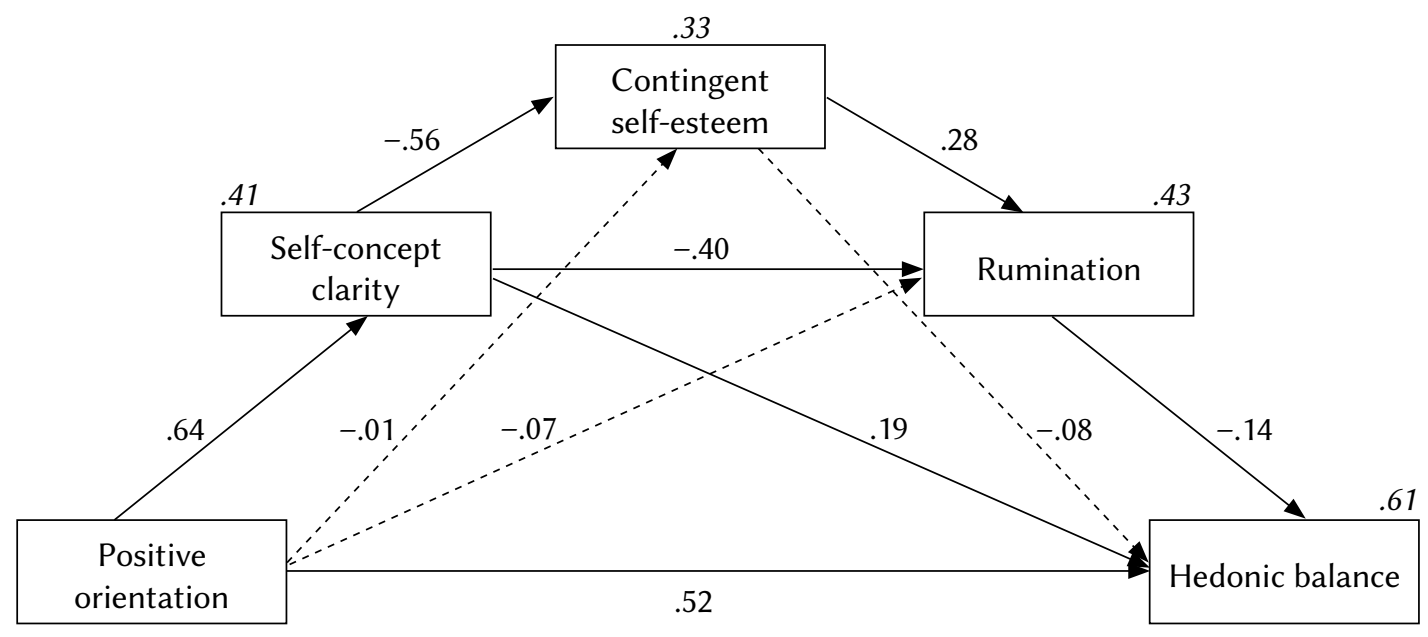

Figure 2. An empirical model of the relationship between positive orientation and hedonic balance mediated by self-concept clarity, contingency of self-esteem and rumination.

bilize and integrate self-knowledge, which in turn may make self-evaluation processes less vulnerable to external conditions. As a consequence, the need to ruminate may decrease. However, other models are theoretically equally reasonable. For example, it is also probable that $\mathrm{PO}$ is related to low anxiety and uncertainty, which initially reduces ruminations. As a result, people construct a clearer self-concept and stable self-esteem.

Assuming that PO is the main predictor and hedonic balance is a dependent variable, we used path analysis to test six alternative models, which differed in the order of mediators. All of them fit the data well or very well (e.g. CFI from .95 to .99 , RMSEA from .001 to .070). However, we chose two models with the best AIC indexes (the range of AIC for all models is from 26.70 to 29.80 ) - both of them contained self-concept clarity as the main mediator, followed in two alternative orders by rumination and contingent self-esteem. Although small differences in AICs made all of the models interpretable - it is probable that all variables related to the adaptive self mutually influenced each other - we decided to describe above only one of the two best fitting models.

\section{DISCUSSION}

The first aim of this study was to investigate the relationship between two sets of variables: one referring to PO and another one referring to what we called the adaptive self-concept. We hypothesized that PO, conceptualized as a higher-order factor standing for a common variance that is shared by self-esteem, satisfaction with life and optimism, predicts specific patterns of self-concept variables enhancing adjustment, namely higher self-concept clarity, lower contingent self-esteem, lower rumination and higher reflection. The results mostly supported our expecta- tions. Simple correlations between the factorial index of PO on one hand, and self-concept clarity, rumination and contingent self-esteem on the other hand, were significant and in line with our hypothesis.

Moreover, a canonical correlation analysis revealed the expected pattern of relations between these two sets of variables. The first canonical function reveals a relation between $\mathrm{PO}$ and a clarified, unconditional concept of the self connected with low motivation to self-analyze. Such sets of canonical variables indicate interdependence between high self-esteem, optimism, life satisfaction and high self-concept clarity, low contingent self-esteem, low rumination and low reflection. Young adults with high levels of self-esteem are optimists and have satisfaction with life; their self-concept is unequivocal and stable and the need for self-consciousness is not very intensive as they do not have a tendency to focus constantly on bad feelings related to experiences from the past and expectations regarding the future.

These results match several theories on the adaptive features of self-concept. For example, Kernis and Goldman (2006) introduced the concept of authenticity, which includes a particular kind of self-awareness characterized by vast knowledge of one's motives, feelings, desires and self-relevant cognitions. What is important, authenticity also contains an ability to integrate "one's inherent polarities into coherent and multifaceted self-representations" (Kernis \& Goldman, 2006, p. 295). Authenticity is strongly and significantly correlated with self-concept clarity $(r=.68)$, contingent self-esteem $(r=-.58)$ and selfesteem $(r=.60)$ (Kernis \& Goldman, 2006).

Contrary to our thinking, that people with high positive orientation reflect on themselves a little bit more than people with low PO, it was found that reflection is weakly and negatively predicted by PO. It was surprising because we expected that people with 
tendencies towards evaluating themselves positively would also be curious about themselves, thus enhancing their level of self-reflection. To explain this, we have to interpret the results in a broader context. Many psychologists have distinguished between two traditions in the study of well-being: hedonic and eudemonic (e.g. Ryan \& Deci, 2001). While the hedonic approach focuses on pleasure and happiness (i.e. subjective well-being), the eudemonic view emphasizes the importance of personal growth, values and virtue as a basis for well-being. Positive orientation has closer affinity with hedonic well-being than with virtues, for it strongly correlates with hedonic balance, and one component of it is satisfaction with life, a variable specific for the hedonic approach (Diener, 1984). Moreover, reflection is associated with the indicators of eudemonia more so than is hedonic well-being. For example, Thomsen, Tønnesvang, Schnieber, and Olesen (2011) found that reflection is moderately related to autonomy, and in other studies it was correlated with personal growth but not with satisfaction with life (Harrington \& Loffredo, 2011). In a recent study, Huta and Waterman (2014) stated that the correspondence between eudaimonia and hedonia ranges from -.30 to .80 for categories of analysis and levels of measurement. When eudaimonia and hedonia are conceptualized as orientations, the trait level correlation is around 0-.40, and it is .30-.60 when conceptualized as experiences. On the other hand, when eudaimonia and hedonia are conceptualized as orientations, the state level correlation is around -.30 , and it is $.50-.80$ when they are conceptualized as experiences. In our study, reflection was conceptualized as an orientation at the state level. Thus, we assumed that reflection was also not positively correlated with PO. However, it still does not answer the question as to why the relationship between the variables, although weak, is negative. It seems probable that this phenomenon is specific to the Polish sample. Note that the correlation between rumination and reflection is stronger in the Polish than in the original sample - while in our study, the correlation was .41, in the United States sample (Trapnell \& Campbell, 1999), it was .22. These results suggest greater similarity of both kinds of thinking about self in the Polish sample, and the possibility of mutual priming.

The second aim of the study was to check the relative contribution of $\mathrm{PO}$ and the adaptive self to hedonic balance. We hypothesized that self-concept clarity, rumination and contingent self-esteem would mediate the relationship between PO and hedonic balance. The results partially confirmed our hypothesis. The proposed model explained much of the variability of hedonic balance - more than half of its variance. PO, after controlling for other variables, remained the strongest predictor of the difference between PA and NA. However, the indirect path between these variables was also significant. It is worth noting that self-concept clarity was the main mediator between PO and hedonic balance, and it significantly increased the amount of the explained variance of the latter variable, as we expected. This result is in accordance, for example, with Higgins' discrepancy theory, which postulates an inverted relationship between perceived discrepancy within the self-system and hedonic balance (more negative and less positive emotions; Higgins, 1987). What is new in our model? It shows the prevailing role of PO in predicting both the level of hedonic well-being and the way people organize their self-knowledge.

Rumination negatively predicted hedonic balance, but the direct relationship between these variables, although significant, was weaker than in the case of self-concept clarity. Such patterns of results show that both variables are different sources of affect. While the unclear conception of the self generates negative emotions such as uncertainty and anxiety (Campbell \& Trapnell, 1999), ruminations, understood as a cognitive reaction to these emotions, independently contribute to less happiness. Such a claim is in line with the contemporary theory of rumination which is currently conceptualized as a maladaptive manner of coping with negative affect, leading to even deeper and prolonged depressive states (Nolen-Hoeksema, 2000).

It is interesting that contingent self-esteem had marginal importance in explaining hedonic balance. It suggests that relying on external standards for self-evaluation does not, per se, change the level of affect, but it can trigger mechanisms (e.g. rumination) that have a negative impact on happiness. In light of our results, self-esteem contingency can be understood as a potential risk factor rather than a cause that directly reduces the level of well-being.

The tested model confirmed that PO directly predicts only self-concept clarity, whereas its relationship with the two other variables - self-esteem contingency and rumination - is mediated by the self-knowledge structure. Such results suggest that a tendency to evaluate the self, life and the future in positive way, which is, to a large extent, inherited (Caprara et al., 2009), has a strong impact on the way the knowledge about the self is shaped by experiences and social processes. High PO facilitates creating a stable, consistent system of self-beliefs that is maintained with a feeling of certainty. As a consequence, a person oriented positively uses inner and stable standards when evaluating the self (Kernis, 2003). In turn, high self-concept clarity and a low contingency of self-esteem reduce the need to self-analyze in a ruminative manner. Thus, for people with a high $\mathrm{PO}$, it is more probable that they process self-relevant information and experiences in such way that it allows for the enhancement of adjustment and well-being.
Positive orientation and the self-concept 
Agnieszka Anna Laskowska, Tomasz Jankowski, Piotr Oleś, Łukasz Miciuk
The study has some limitations. It is a purely correlational study conducted in one country (Poland) on a sufficient but not representative sample. The results concerning the mutual relationship between PO and self-concept should be replicated in other samples. Moreover, possible replications should include other ways of assessment of variables; for example, frequency of affect could be measured instead or together with its intesity. Similarly, the mediating analyses concerning self-concept clarity, as well as internal relationships inside the self-structure, should be verified in further, experimental studies.

Ethical approval: All procedures performed in studies involving human participants were in accordance with the ethical standards of the institutional and/or national research committee and with the 1964 Helsinki declaration and its later amendments or comparable ethical standards.

Informed consent was obtained from all individual participants included in the study.

\section{References}

Alessandri, G., Caprara, G. V., \& Tisak, J. (2012). The unique contribution of positive orientation to optimal functioning: Further explorations. European Psychologist, 17, 44-54.

Baumeister, R. F., Campbell, J. D., Krueger, J. I., \& Vohs, K. D. (2003). Does high self-esteem cause better performance, interpersonal success, happiness, or healthier lifestyles? Psychological Science in the Public Interest, 4, 1-44.

Burnham, K. P., \& Anderson, D. R. (2002). Model Selection and Multimodel Inference. New York: Springer Verlag.

Campbell, J. D., Assanand, S., \& Di Paula, A. (2003). The structure of self-concept and its relation to psychological adjustment. Journal of Personality, 71, 115-140.

Campbell, J. D., Trapnell, P. D., Heine, S. J., Katz, I. M., Lavallee, L. F., \& Lehman, D. R. (1996). Self-concept clarity: Measurement, personality correlates, and cultural boundaries. Journal of Personality and Social Psychology, 70, 141-156.

Caprara, G. V. (2009). Positive orientation: Turning potentials into optimal functioning. The Bulletin of the European Health Psychologist, 11, 46-48.

Caprara, G. V., Alessandri, G., Eisenberg, N., Kupfer, A., Steca, P., Caprara, M. G., Yamaguchi, S., Fukuzawa, A., \& Abela, J. (2012a). The Positivity Scale. Psychological Assessment, 24, 701-712.

Caprara, G. V., Alessandri, G., Trommsdorff, G., Heikamp, T., Yamaguchi, S., \& Suzuki, F. (2012b). Positive orientation across countries. Journal of Cross-Cultural Psychology, 43, 77-83.
Caprara, G.V., Eisenberg, N., \& Alessandri, G. (2017). Positivity: the dispositional basis of happiness. Journal Happiness Study, 18, 353-371.

Caprara, G. V., Fagnani, C., Alessandri G., Steca P., Gigantesco, A., Cavalli-Sforza, L. L., \& Stazi M. A. (2009). Human optimal functioning: The genetics of positive orientation towards self, life, and the future. Behaviour Genetics, 39, 277-284.

Caprara, G. V., \& Steca, P. (2005). Affective and social self-regulatory efficacy beliefs as determinants of positive thinking and happiness. European Psychologist, 10, 275-286.

Caprara, G. V., Steca, P., Gerbino, M., Paciello, M., \& G. M. Vecchio. (2006). Looking for adolescents' well-being: self-efficacy beliefs as determinants of positive thinking and happiness, Epidemiologia e Psychiatria Sociale, 15, 30-43.

Crocker, J., Brook, A. T., Niiya, Y., \& Villacorta, M. (2006). The pursuit of self-esteem: Contingencies of self-worth and self-regulation. Journal of Personality, 74, 1749-1771.

Deci, E. L., \& Ryan, R. M. (2000). The "what" and "why" of goal pursuits: Human needs and the self-determination of behavior. Psychological Inquiry, 11, 227-268.

Deci, E. L., \& Ryan, R. M. (2008). Hedonia, eudaimonia, and well-being: An introduction. Journal of Happiness Studies, 9, 1-11.

Diener, E. (1984). Subjective well-being. Psychological Bulletini, 95, 542-575.

Diener, E., \& Diener, M. (1995). Cross-cultural correlates of life satisfaction and self-esteem. Journal of Personality and Social Psychology, 68, 653-663.

Diener, E., Emmons, R. A., Larsen, R. J., \& Griffin, S. (1985). The Satisfaction with Life Scale. Journal of Personality Assessment, 49, 71-75.

Diener, E., Fujita, F., Tay, L., \& Biswas-Diener, R. (2012). Purpose, mood, and pleasure in predicting satisfaction judgements. Social Indicators Research, 105, 333-341.

Fajkowska, M., \& Marszał-Wiśniewska, M. (2009). Właściwości psychometryczne Skali Pozytywnego i Negatywnego Afektu - Wersja Rozszerzona (PANAS-X). Wstępne wyniki badań w polskiej próbie [Psychometric properties of Positive and Negative Affect Schedule-Expanded Form (PANAS-X). Study on Polish sample]. Przeglad Psychologiczny, 52, 355-387.

Fredrickson, B. L. (2009). Positivity. New York: Three Rivers Press.

Harrington, R., \& Loffredo, D. A. (2011). Insight, rumination, and self-reflection as predictors of well-being. The Journal of Psychology, 145, 39-57.

Heikamp, T., Alessandri, G., Laguna, M., Petrovic, V., Caprara, M. G., \& Trommsdorff, G. (2014). Crosscultural validation of the positivity-scale in five European countries. Personality and Individual Differences, 71, 140-145. 
Higgins, E. T. (1987). Self-Discrepancy: A theory relating self and affect. Psychological Review, 94, 319-340.

Hu, L., \& Bentler, P. M. (1999). Cutoff criteria for fit indexes in covariance structure analysis: Conventional criteria versus new alternatives. Structural Equation Modeling, 6, 1-55.

Huta, V., \& Waterman, A. S. (2014). Eudaimonia and its distinction from hedonia: Developing a classification and terminology for understanding conceptual and operational definitions. Journal of Happiness Studies, 15, 1425-1456.

Jankowski, T. (2008). Integrująca rola uważności w kształtowaniu koncepcji siebie [Mindfulness as an integrating factor for the self-concept structure]. Przeglad Psychologiczny, 51, 443-464.

Kernis, M. H. (2003). Toward a conceptualization of optimal self-esteem. Psychological Inquiry, 14, 1-26.

Kernis, M. H. (2006). Self-esteem: Issues and Answers. New York and Hove: Psychology Press.

Kernis, M. H., \& Goldman, B. M. (2006). A multicomponent conceptualization of authenticity: Research and theory. In M. P. Zanna (Ed.), Advances in Experimental Social Psychology (vol. 38, pp. 284-357). San Diego, CA: Academic Press.

Kernis, M. H., Lakey, C. E., \& Heppner, W. L. (2008). Secure versus fragile high self-esteem as a predictor of verbal defensiveness: Converging findings across three different markers. Journal of Personality, 76, 477-512.

Kuster, F., Orth, U., \& Meier, L. L. (2012). Rumination mediates the prospective effect of low self-esteem on depression: A five-wave longitudinal study. Personality and Social Psychology Bulletin, 38, 747-759.

Laguna, M., Alessandri, G., \& Caprara, G. V. (2017). How do you feel about this goal? Goalrelated affect, positive orientation, and personal goal realization in the family domain. Journal of Happiness Study, 18, 827-842.

Lauriola, M., \& Iani, L. (2015). Does positivity mediate the relation of extraversion and neuroticism with subjective happiness? PLoS One, 10, 1-16.

Lauriola, M., \& Iani, L. (2017). Personality, positivity and happiness: A mediation analysis using a bifactor model. Journal of Happiness Studies, 18, 1659-1682.

Leary, M. R., \& Tangney, J. P. (2012). The self as an organizing concept in the social and behavioral sciences. In M. R. Leary \& J. P. Tangney (Eds.), Handbook of self and identity (2nd ed., pp. 1-18). New York: Guilford.

Linville, P. W. (1985). Self-complexity and affective extremity: Don't put all your eggs in one cognitive basket. Social Cognition, 3, 94-120.

McCrae, R. R., \& Costa, P. T. (1999). A five-factor theory of personality. In L. A. Pervin \& O. P. John
(Eds.), Handbook of personality (pp. 139-153). New York: Guilford.

Miciuk, Ł., Jankowski, T., Laskowska, A., \& Oleś, P. (2016). Positive orientation and five factor model. Polish Psychological Bulletin, 47, 141-148.

Nolen-Hoeksema, S. (2000). The role of rumination in depressive disorders and mixed anxiety/depressive symptoms. Journal of Abnormal Psychology, 109, 504-511.

Oleś, P. K., Alessandri, G., Oleś, M., Bąk, W., Jankowski, T., Laguna, M., \& Caprara, G. V. (2013). Positive orientation and generalized self-efficacy. Studia Psychologica, 55, 47-59.

Oleś, P., \& Jankowski, T. (2018). Positive orientation a common base for hedonistic and eudemonistic happiness? Applied Research Quality Life, 13, 105117.

Paradise, A. W., \& Kernis, M. H. (1999). Development of the Contingent Self-Esteem Scale. Unpublished data, University of Georgia.

Peterson, C., \& Seligman, M. E. P. (2004). Character strengths and virtues: A classification and handbook. New York: Oxford University Press/Washington, DC: American Psychological Association.

Preacher, K. J., \& Hayes, A. F. (2008). Asymptotic and resampling strategies for assessing and comparing indirect effects in multiple mediator models. Behavior Research Methods, 40, 879-891.

Ritchie, T. D., Sedikides, C., Wildschut, T., Arndt, J., \& Gidron, Y. (2011). Self-concept clarity mediates the relation between stress and subjective wellbeing. Self and Identity, 10, 493-508.

Rosenberg, M. (1965). Society and the adolescent image. Princeton, NJ: Princeton University Press.

Ryan, R. M. (1995). Psychological needs and the facilitation of integrative processes. Journal of Personality, 63, 397-427.

Ryan, R. M., \& Deci, E. L. (2001). On happiness and human potentials: A review of research on hedonic and eudaimonic well-being. In S. Fiske (ed.), Annual review of psychology (vol. 52, pp. 141-166). Palo Alto, CA: Annual Reviews, Inc.

Sargent, J. T., Crocker, J., \& Luhtanen, R. K. (2006). Contingencies of self-worth and symptoms of depression in college students. Journal of Social and Clinical Psychology, 25, 628-646.

Scheier, M. F., Carver, C. S., \& Bridges, M. W. (1994). Distinguishing optimism from neuroticism (and trait anxiety, self-mastery, and self-esteem): a reevaluation of the Life Orientation Test. Journal of Personality and Social Psychology, 67, 10631078.

Sherry, A., \& Henson, R. K. (2005). Conducting and interpreting canonical correlation analysis in personality research: a user-friendly primer. Journal of Personality Assessment, 84, 37-48.

Showers, C. J. (2002). Integration and compartmentalization: A model of self-structure and self-
Positive orientation and the self-concept 
Agnieszka Anna

Laskowska,

Tomasz Jankowski,

Piotr Oleś,

Łukasz Miciuk change. In D. Cervone \& W. Mischel (Eds.), Advances in Personality Science (pp. 271-291). New York: Guilford.

Thomsen, D. K., Tønnesvang, J., Schnieber, A., \& Olesen, M. H. (2011). Do people ruminate because they haven't digested their goals? The relations of rumination and reflection to goal internalization and ambivalence. Motivation \& Emotion, 35, 105-117.

Trapnell, P. D., \& Campbell, J. D. (1999). Private self-consciousness and the Five-Factor Model of personality: Distinguishing rumination from reflection. Journal of Personality and Social Psychology, 76, 284-304.

Watson, D., \& Clark, L. A. (1994). The PANAS-X. Manual for the positive and negative schedule expanded form. The University of lowa.

Watson, D., Suls, J., \& Haig, J. (2002). Global self-esteem in relation to structural models of personality and affectivity. Journal of Personality and Social Psychology, 83, 185-197.

Yildiz, M. A. (2017). Pathways to positivity from perceived stress in adolescents: multiple mediation of emotion regulation and coping strategies. Current Issues in Personality Psychology, 5, 272-284. 